\title{
MUNDIALIZAÇÃO E TRABALHO: UM DEBATE SOBRE A FORMAÇÃO DOS TRABALHADORES NO BRASIL
}

\author{
Carlos Lucena ${ }^{\mathrm{i}}$ \\ Robson Luiz de Françai ${ }^{\text {ii }}$ \\ Gabriel Humberto Muñoz Palafox ${ }^{\text {iii }}$
}

\section{RESUMO:}

Este trabalho discute as políticas públicas voltadas para a formação profissional no Brasil. Problematiza a dialética entre o trabalho, a formação humana e os complexos processos sociais presentes nas dimensões econômica, política e social que se materializam através da divisão internacional do trabalho. Demonstra como as relações de trabalho são elaboradas em um movimento internacional de reordenação geográfica do capital, em que os trabalhadores globalmente têm uma relação com o trabalho incerto, em que esse não consegue impor seu caráter humano. No caso do Brasil, considerando o agravamento da crise do capital que se acentua em países em desenvolvimento, as desigualdades sociais também aumentaram devido ao fator educação que separa ainda mais as diferenças de classe e a ascensão social, além de ressaltar a influência da economia capitalista no campo educativo, não atendendo e oferecendo educação de qualidade para todos, não desenvolvendo as concepções sobre as condições impostas aos menos favorecidos, que são esmagados pela política, pela falta de acesso à saúde, pelas relações desiguais de classes sociais, e pelas demais dinâmicas presentes em nossa sociedade que contribuem para a continuidade desta situação para essa população.

Palavras-chave: Formação profissional. Política pública. Educação. Trabalho. Formação humana.

\section{MONDIALIZATION AND WORK: A DISCUSSION ON THE TRAINING OF WORKERS IN BRAZIL}

\begin{abstract}
:
This article argues about public politicals directed to Professional education in Brazil. It contrasts the dialect between work, human education and the complex social process present in economic political and social surroundings. These elements are materialized by international work division. It shows how work relations are done in an international movement of capital's geography reordination, where the worker, globally, have a relation with uncertain work where this doesn't get to command his human character. In Brazil case, considering that capital crisis stresses in developed countries, the social inequalities increase too, because of education factor which separate the social class differences and social rise, besides, this it shows up the influence of capitalist economy in the educative environment. The education factor doesn't attend and offered quality education for everybody, it doesn't develop the conceptions about conditions imposed to the less favoured people who are prejudiced by political, lack of heath access, different relations of social classes and dynamics presented in our society, which increase the bad situation to the population Key-word: Professional educational. Public political. Educational. Work. Human education.
\end{abstract}




\section{Introdução}

As percepções sobre a formação profissional com o avanço do capitalismo monopolista nas últimas décadas são percebidas através da dialética entre o trabalho, a formação humana e os complexos processos sociais presentes na dimensão econômica, política e social. As políticas públicas voltadas para a formação de trabalhadores influenciam e são influenciadas pelas mediações dialéticas existentes em seu tempo, entre as quais a divisão internacional do trabalho constitui-se em um fator considerável.

Quando analisamos a inserção de um país na divisão internacional do trabalho, devemos considerar que essa é expressão de diferenças e desigualdades, materialização das relações de poder e dominação do seu tempo; exemplo fundamental da constituição de uma produção científica heterogênea que circula de diferentes formas no planeta. Ao fazermos essa afirmação, tomamos como princípio que os processos formativos humanos voltados para a formação dos trabalhadores são expressões da complexa lógica do trabalho, expressão das relações da humanidade com a natureza que dá sentido e objetiva a sua existência. Marx afirma em os Grundisse que a

[...] natureza não constrói máquinas, nem locomotivas, nem estradas de ferro, nem telégrafos elétricos, nem máquinas automáticas de tecer, etc.; isso são produtos da indústria humana, da matéria natural, transformada em instrumentos da vontade e da atividade humana sobre a natureza. São instrumentos do cérebro humano, criados pela mão do homem, órgãos materializados do saber (MARX, 1980, p. 52).

Engels em $O$ Anti During problematiza a relação humana com a natureza, afirmando que a liberdade é a expressão da consciência das necessidades naturais, um produto da evolução histórica humana e suas relações com a natureza. Os primeiros homens

[...] que se levantaram do reino animal eram, em todos os pontos essenciais de suas vidas, tão pouco livres quanto os próprios animais; cada passo dado no caminho da cultura é um passo no caminho da liberdade. Nos primórdios da história da humanidade, realizou-se a descoberta que permitiu converter o movimento mecânico em calor: a produção do fogo pela fricção; o progresso tem, atualmente, como sua etapa terminal, a descoberta que transforma, inversamente, o calor em movimento mecânico: a máquina a vapor. E apesar do colossal abalo de libertação que a máquina a vapor trouxe ao mundo social - e que até hoje ainda não deu sequer a metade de seus frutos - é indubitável que a produção do fogo pela fricção, nos tempos primitivos, foi superior àquela descoberta como condição emancipadora. $\mathrm{O}$ fogo, obtido dessa forma, foi que permitiu ao homem o domínio sobre uma força da natureza, emancipando-o definitivamente das limitações do mundo animal (ENGELS, s/d, p. 65).

Engels aprofunda essa discussão em $A$ dialética da natureza, afirmando, em negação aos princípios metafísicos relativos à origem em explicação da humanidade, que foi o trabalho, resultado de ações racionais do homem com a natureza, objetivados à sua própria 
sobrevivência, que deu sentido e consciência aos seres humanos. A humanidade foi inventada pelo trabalho que colocou à ela condições para o desenvolvimento da linguagem, da sociedade, da ciência e da tecnologia. Podemos dizer que Engels utilizou o conceito de trabalho na sua forma abstrata como pressuposto que diferenciava os homens dos animais. Essa afirmação se comprova quando se verifica as comparações realizadas entre o homem e a águia. Ele ilustrou essa questão afirmando que o olho da águia enxerga muito mais longe do que o olho do homem, não existindo comparação quanto ao alcance de um e de outro. Porém, o olho do homem, mesmo sendo restrito em relação ao da águia, enxerga e interpreta o mundo não apenas nas fronteiras do instinto, mas, sim, pela racionalidade que dá sentido e substância àquilo que vê. Essa afirmação de Engels influenciou profundamente Marx na elaboração da célebre passagem no Livro Primeiro de O Capital, afirmando que o

[...] trabalho é um processo entre o homem e a Natureza, um processo em que o homem, por sua própria ação, media, regula e controla seu metabolismo com a Natureza. Ele mesmo se defronta com a matéria natural como uma força natural. Ele põe em movimento as forças naturais pertencentes à sua corporalidade, braços e pernas, cabeça e mão, a fim de apropriar-se da matéria natural como uma forma útil para a sua própria vida. Ao atuar, por meio desse movimento, sobre a Natureza externa a ele e ao modificá-la, ele modifica, ao mesmo tempo, sua própria natureza. Ele desenvolve as potências nela adormecidas e sujeita ao jogo de suas forças a seu próprio domínio. Não se trata aqui das primeiras formas instintivas, animais de trabalho. $\mathrm{O}$ estado em que o trabalhador se apresenta no mercado como vendedor de sua própria força de trabalho deixou para fundo dos tempos primitivos o estado em que o trabalho humano não se desfez ainda de sua primeira forma instintiva. Pressupomos o trabalho numa forma em que pertence exclusivamente ao homem. Uma aranha executa operações semelhantes às do tecelão, e a abelha envergonha mais de um arquiteto humano com a construção do favo de suas colméias. Mas, o que distingue de antemão, o pior arquiteto da melhor abelha é que ele construiu o favo em sua cabeça, antes de construí-lo na cera. No fim do processo de trabalho obtémse um resultado que já no início deste existiu na imaginação do trabalhador, e, portanto idealmente. Ele não apenas efetuou uma transformação da forma da matéria natural; realiza, ao mesmo tempo, na matéria natural seu objetivo, que ele sabe que determina, como lei, a espécie e o modo de sua atividade e ao qual tem de subordinar a sua vontade (MARX, 1985, p. 149-150).

O trabalho como a consolidação do modo de produção capitalista, relacionado ao avanço da maquinaria industrial passa por uma importante inversão. Marx no Capítulo VI Inédito do Livro Primeiro de $O$ Capital afirma que os trabalhadores são percebidos gradativamente como estranhos à maquinaria, autômatos da própria máquina. Desenvolve-se uma inversão de relações entre o trabalho e seus instrumentos, relações que têm como explicação a história do trabalho no capitalismo. Essa se explica pelo pressuposto que, se antes as máquinas foram criadas como extensão dos braços dos homens, agora são os homens que se transformaram, em maioria absoluta, nos braços dessas máquinas.

Marx também aponta essa questão nos Grundisse, demonstrando que os trabalhadores se transformam em acessórios conscientes da maquinaria industrial, um acessório vivo da máquina, um mero meio de ação para uma atividade estranha a eles. "A ciência do capitalismo 
não existe mais no cérebro dos trabalhadores, pelo contrário, se manifesta nas máquinas que agem sobre os trabalhadores como uma força estranha, como o próprio poder da máquina" (MARX, 1980, p. 39).

A máquina já não tem nada de comum com o instrumento do trabalhador individual. A atividade manifesta-se muito mais como pertencente à máquina, ficando o operário a vigiar a ação da máquina e protegê-la de avarias. Com a ferramenta era diferente. $\mathrm{O}$ trabalhador animava a ferramenta com sua arte e criatividade. Com efeito, a máquina é que passa a ter virtuosidade, pois as leis mecânicas em seu interior dotaram-na de alma. [...] Nos numerosos pontos do sistema mecânico, o trabalho aparece como corpo consciente, sob a forma de alguns trabalhadores vivos. Dispersos, submetidos ao processo de conjunto da maquinaria, não forma mais do que um elemento do sistema, cuja unidade não reside nos trabalhadores vivos, mas na maquinaria viva (ativa) que, em relação à atividade isolada e insignificante do trabalho vivo, aparece como um organismo gigantesco (MARX, 1980, p. 38-39).

Quando problematizamos esse processo de inversão imposto pelo avanço do capitalismo monopolista nas últimas décadas, verificamos que esse avanço materializa contradições que colocam possibilidades e limites para a burguesia e à reprodução do capital. Entre as possibilidades estão as formas de exploração cada vez mais substantivas, tanto no âmbito da mais-valia absoluta, como na mais-valia relativa. $O$ investimento em capital constante, em detrimento do capital variável, reduz a velocidade da reprodução do capital, uma vez que a maquinaria industrial se paga através da depreciação. As saídas encontradas estão presentes na adoção de estratégias voltadas para a exploração máxima dos trabalhadores. A eficiência do capitalista está na sua capacidade e inventividade de assimilação máxima do trabalho na sua dimensão objetiva e subjetiva, transformando o tempo livre, a imaginação e a resistência dos trabalhadores em mais trabalho. Essas iniciativas se consolidam com a antecipação das reivindicações dos trabalhadores, incorporando seus anseios e aspirações aos interesses das empresas, bem como, em nível estrutural, à promoção de novas elites que se manifestam em governos eleitos pelos trabalhadores com potencial de promover medidas que prejudiquem os próprios trabalhadores. É nesse sentido que se criam e recriam ideologias voltadas para a exploração máxima das capacidades dos trabalhadores que se manifestam em políticas educacionais voltadas para esse fim, sendo o Brasil um dos exemplos.

Relacionado dialeticamente às possibilidades de reprodução do capital apontadas acima, vemos os limites que se manifestam na constituição de crises econômicas cíclicas do capitalismo que afetam a reprodução do capital e as respostas dos homens de negócios para a recomposição desse processo de acumulação. O que se verifica é uma aposta radical na economia de mercado como instrumento da liberdade individual. ${ }^{\text {iv }}$ A adoção de novas formas de gestão e organização da produção se explica por meio do movimento transnacional da economia política imposta pela burguesia internacional que constroe imperativos legitimados pela expansão incontrolável do capital que impõem a exploração máxima da força de trabalho tal qual afirmamos anteriormente.

Não podemos desconsiderar que entre as iniciativas dos homens de negócios, objetivadas no incremento da reprodução do capital, a busca do envolvimento dos trabalhadores com os interesses das empresas se intensifica. Quanto mais as empresas 
incorporam os interesses dos trabalhadores aos seus, construindo alternativas para que os interesses sejam homogeneizados, consolidam-se os alicerces para que o saber dos trabalhadores se volte contra os próprios trabalhadores, pois é através dele que as empresas sistematizam a produção, elevando as fronteiras do trabalho alienado. O saber dos trabalhadores ao ser codificado deixa gradativamente de ser misterioso e perde o seu potencial de resistência, um dos fundamentos principais da sua qualificação.

É com essas questões que se problematiza a inserção dos trabalhadores, sua qualificação e a importância da educação nesse complexo e contraditório processo. A luta dos trabalhadores passa pela incessante busca do conhecimento, mesmo entendendo que esse não se explica por si só, mas seu maior acesso ou não, se justifica nas mediações da sociedade capitalista. É o que já demonstrava Marx, ao debater a condição miserável da educação oferecida aos trabalhadores na Inglaterra do século XIX.

Ao visitar uma dessas escolas expedidoras de certificados fiquei tão chocado com a ignorância do mestre-escola que lhe disse: 'Por favor, o senhor sabe ler? Sua resposta foi : Ah! Algo (summat). E, como justificativa, acrescentou: De todos os modos estou à frente dos meus alunos' [...] A primeira escola que visitamos era mantida por uma Mrs. Ann Killin. Quando lhe pedi para soletrar o sobrenome, ela logo cometeu um erro ao começar com a letra C, mas, corrigindo-se imediatamente, disse que ser sobrenome começava com K. Olhando sua assinatura nos livros de assentamento escolares, reparei, no entanto, que ela o escrevia de vários modos, enquanto sua letra não deixava nenhuma dúvida quanto a sua incapacidade de lecionar. Ela mesma também reconheceu que não sabia manter o registro [...] Numa segunda escola, encontrei uma sala de aula de 15 pés de comprimento e 10 pés de largura e nesse espaço contei 75 crianças que estavam grunhindo algo ininteligível. Não é, porém, apenas nessas covas lamentáveis que as crianças recebem certificados escolares, mas nenhuma instrução, pois, em muitas escolas onde o professor é competente, os esforços dele são de pouca valia em face ao amontoado atordoante de crianças de todas as idades, a partir de 3 anos. Sua receita, mísera no melhor dos casos, depende totalmente do número de pence, recebidos do maior número possível de crianças que seja possível empilhar num quarto. A isso acresce o parco mobiliário escolar, carência de livros e outros materiais didáticos, bem como o efeito deprimente, sobre as pobres crianças, de uma atmosfera fechada e fétida. Estive em muitas dessas escolas, onde vi séries inteiras de crianças não fazendo absolutamente nada; e isso é certificado como frequiência escolar e, na estatística oficial, tais crianças figuram como sendo educadas (educated) (MARX, 1988, p. 25).

Marx retrata a educação oferecida aos trabalhadores nas indústrias metalúrgicas de estamparia inglesa, problematizando que, em uma sociedade de classes organizada nas fronteiras da reificação crescente, o acesso ao conhecimento é heterogêneo e diversificado.

Toda criança, antes de ser empregada numa dessas estamparias, deve ter freqüentado a escola ao menos por 30 dias e por não menos de 150 horas durante 6 meses que precedem imediatamente o primeiro dia de seu emprego. Durante a continuidade de seu emprego na estamparia, precisa igualmente freqüentar a escola por um período de 30 dias e de 150 horas a cada período

Revista HISTEDBR On-line, Campinas, n. Especial, p.147-161, mai.2009 - ISSN: 1676-2584 
semestral. [...] Em circunstâncias normais, as crianças freqüentam a escola de manhã e à tarde por 30 dias, 5 horas por dia e, após o decurso dos 30 dias, quando estatutária global de 150 horas foi atingida, quando eles, para usar seu linguajar, acabaram o seu livro, voltam para a estamparia, onde ficam de novo 6 meses até que vença outro prazo de freqüência escolar, e então ficam novamente na escola até que acabem o livro novamente. [...] Muitos jovens que freqüentavam a escola durante as 150 horas requeridas, quando voltam ao término de 6 meses de permanência, estão no mesmo ponto em que estavam no começo. [...] Eles naturalmente perderam tudo quanto tinham adquirido com sua freqüência anterior à escola (MARX, 1988, p. 26).

Ao mesmo tempo devemos considerar que, mesmo com a elevação do acesso a níveis escolares mais elevados ,a qualificação dos trabalhadores não eleva. O aumento do nível de escolaridade atenta à exploração gratuita, por parte da empresa, dos saberes formais dos trabalhadores adquiridos nas escolas, consolidando relações em que mesmo diplomados em nível superior, exercem funções não condizentes com a sua formação intelectual. Esses atuam como executantes e, através de políticas empresariais de sugestões no processo produtivo, têm seus saberes solicitados em troca de uma "promessa subjetiva de continuidade no emprego", enquanto que na realidade não recebem nada por isso. Em alguns casos, o risco que correm é que suas sugestões voltem-se contra eles mesmos, racionalizando, ainda mais, o processo produtivo e custando o próprio emprego de quem as criou: a criação volta-se contra o próprio criador.

O aumento do nível de escolaridade não significa elevação de sabedoria operária, e muito menos a construção de homens superiores que visualizam além do trabalho alienado. $\mathrm{O}$ desafio consiste na união entre o saber e o fazer, na junção de algo que as constantes transformações na organização técnica e social da produção capitalista separam e que está muito distante dos trabalhadores. A qualificação fragmentada e despolitizada constitui-se no esvaziamento do conteúdo dos trabalhadores. A noção de formação profissional deve ser construída pelos próprios trabalhadores, recuperando a historicidade das suas lutas e reivindicações, constituindo-se em um grande desafio de intervenção dos próprios trabalhadores. Para isso, é necessária a recuperação de experiências nacionais sem perder de referência as mediações internacionais, problematizando suas contradições, identificando projetos e concepções de mundo que aparentemente são neutros, mas essencialmente não o são.

\section{Algumas considerações sobre a formação profissional no Brasil}

A análise da formação profissional no Brasil corrobora com as preocupações citadas anteriormente. Não podemos desconsiderar que as mediações da humanidade com a natureza impulsionam processos de formação humana, mediam relações sociais e proporcionam processos de disputa. A formação obtida no contexto educacional brasileiro é contraditória, uma vez que tanto manifesta processos de resistência com relação a afirmações dos interesses da reprodução do capital, bem como materializa concepções que, baseadas na noção de individualidade, responsabilizam os trabalhadores pela sua formação e manutenção no mercado de trabalho.

Essa é uma contradição que atravessa o capitalismo e seus processos de formação

Revista HISTEDBR On-line, Campinas, n. Especial, p.147-161, mai.2009 - ISSN: 1676-2584 
humana. O mercado de trabalho ocasiona desigualdades e discriminações devido à concentração de renda nas mãos de poucos que conseguem melhores condições de trabalho, enquanto que parcela considerável fica desempregada e submissa a empregos precários, sem nenhuma perspectiva de ascensão social e de permanência no mercado de trabalho. Segundo Pochmann (2004), a dinâmica do mercado de trabalho é extremamente excludente e danifica as contribuições que a educação oferece, aumentando, consequentemente, as desigualdades sociais existentes no País. As taxas de desemprego vêm aumentando para a população mais escolarizada, o que acaba por exceder mão-de-obra para o mercado nesse seguimento social. Desta maneira, a elevação dos níveis de escolaridade - num quadro de estagnação econômica, baixo investimento em tecnologia e precarização do mercado de trabalho - acaba se mostrando insuficiente para potencializar a geração do trabalho (POCHMANN, 2004).

Pode-se perceber que os melhores empregos acabam com os mais ricos, sendo que os menos favorecidos e com alta escolaridade ficam desempregados, além de sofrer preconceitos raciais e de classe. É necessário que ocorra uma expansão da escolaridade, não apenas do ponto de vista produtivo, como também da cidadania.

A crise atual do capitalismo, bem como o seu processo de reorganização e a construção de uma nova sociabilidade no Brasil, dentro de uma ótica subalterna ao capital (ARRIGHI, 1997), apresenta-se como um período de amplas e profundas transformações nos pólos científicos e científico-tecnológico, alteração no interior dos processos de trabalho, reorganização dos Estados etc.

Essas mudanças, em um contexto amplo de Estado, são caracterizadas por dois períodos distintos. O primeiro deles é descrito por Hobsbawn (1995), sendo considerado como "Era do Ouro", que se evidencia com um amplo crescimento econômico e de estabilidade e com uma crescente produção e consumo. Por outro lado, evidencia-se, também, nesse contexto, a política do pleno emprego. O segundo período é caracterizado pela globalização e mundialização de capital, discutido por Ianni (1996) e François Chesnais (1998) período que revela as políticas neoliberais e responsável pelas profundas mudanças no contexto das políticas sociais, do trabalho, da reestruturação produtiva, bem como das reformas estatais que visam garantir de um lado a desestatização da economia e, por outro, a presença do estado com base em mecanismos de regulação da economia.

No Brasil, o processo de desestatização e regulação inicia-se nos anos 1990, com o governo Collor de Mello e, a seguir, com Fernando Henrique Cardoso, no discurso de modernização econômica e produtiva do país. As principais conseqüências da implementação desse modelo refletem na fragilização dos direitos trabalhistas, no esvaziamento do poder de negociação coletiva de trabalho e no acirrado discurso de qualificação do trabalhador como requisito fundamental para a manutenção no mercado de trabalho.

Rodrigues (1998) afirma que o que ocorreu no Brasil, nesse período, foi a tentativa de instaurar uma hegemonia no Brasil tão desejada pela burguesia, implementando seu projeto baseado na ideologia neoliberal, na flexibilidade, na descentralização e autonomia, e na privatização. O ideário neoliberal se constitui como uma prática ideológica com priorização do social que transforma todo o planejamento em mercado, ressaltando o individualismo e, principalmente, o capitalismo.

Segundo Ianni (1998), o neoliberalismo possui cinco bases fundamentais: práticas ideológicas; cultura; desencantamento do mundo; diplomacia e globalização. As práticas ideológicas funcionam como troca de hábitos, de atitudes, comportamentos, idéias, procedimentos, enfim tudo que objetive expandir os espaços para o mercado. A cultura atua 
influenciando a população pela dinâmica da economia. O processo de desencantamento do mundo ocorre baseado na intensificação de idéias inspiradas na "razão instrumental, traduzidas em pragmatismo, racionalização, modernização, etc." (IANNI, 1998). A diplomacia reproduz e dissemina os ingredientes nazi-fascistas, difundindo por todo o mundo e intensificando a globalização. Essa, por sua vez, provoca mudanças nos quadros sociais, interferindo nos territórios a fim de expandir fronteiras econômicas pelo mundo, visando à expansão do capitalismo. Isso tudo tem sido o que produz e reproduz as classes subalternas, a pobreza, o desemprego, resultando em violência, em protestos, lutas sociais e diversas formas de reivindicações que expressam as desigualdades sociais.

Segundo Ianni (1998), há uma ordem social global que não se parece com o antigo "equilíbrio" entre os Estados Nacionais nas suas relações internacionais (a bipolaridade da era da "Guerra Fria", por exemplo), mas que demonstra que o discurso do globalismo, como apologia dos "valores" do mercado, não passa de uma ideologia que pressupõe esta ordem, embora a negue como estrutura mundial de poder que sustenta um sistema econômico causador desta situação de miséria social e destituição de direitos.

Ianni radicaliza este ponto de vista teórico:

Sim, as organizações multilaterais e as corporações transnacionais são novas, poderosas e ativas estruturas mundiais de poder. Elas se sobrepõem e impõem aos Estados nacionais, compreendendo extensos segmentos das sociedades civis, isto é das suas forças sociais. [...] Sim, já se formaram e continuam a desenvolverem-se estruturas globais de poder, respondendo aos objetivos e às práticas dos grupos, classes ou blocos de poder organizados em escala realmente global (IANNI, 1998, p. 20, grifos do autor)

Desta forma, a gestão capitalista da crise, que se esconde por trás do discurso triunfante do pensamento único neoliberal e da ideologia do globalismo, é administrada por intelectuais, instituições, empresas, governos e classes sociais que formam uma coalizão que se contrapõe a uma noção, como a da universalização da apropriação dos direitos humanos na condição de forma de desenvolvimento econômico-social. A gestão da exclusão social é um subproduto lógico e real deste processo social de caráter conservador, pois perpetua a desigualdade social e a pobreza estrutural.

Fica claro, portanto, que em meio à evolução capitalista do mundo, as relações de trabalho sofrem profundas modificações e a principal delas é o conceito de trabalho visto como uma mercadoria. Além disso, segundo Chesnais (1998) e Ianni (1996) há uma reordenação geográfica do capital em que os trabalhadores globalmente passaram a ter uma relação com o trabalho incerto, em que esse não consegue impor seu caráter humano. Outra característica do trabalho é o distanciamento entre o empregador e empregado, tomando como base as formas de gestão do trabalho, reduzindo o trabalhador a uma massa desprovida de individualidades e subjetividades.

Portanto, a transitoriedade é a marca de um estilo de vida, que se estabelece pelo não comprometimento com o "outro" e ausência quase que total da solidariedade social. Nesse contexto, o subemprego, fruto do expressivo desemprego estrutural, é uma realidade. Sem direitos e sem deveres legais, o subempregado automaticamente se torna um excluído à margem do processo produtivo e social do Estado. Outra característica no contexto do capitalismo avançado é a alta qualificação/formação atrelada ao crescimento de baixos 
salários. Com a concorrência acirrada e o alto índice de desemprego, os trabalhadores, principalmente os mais jovens, são submetidos à aceitação de uma remuneração aquém de suas obrigações e necessidades, fator que ajuda na manutenção e disseminação das agruras econômicas e dos níveis de insegurança (PETRAS, 1999).

As desigualdades sociais também aumentaram devido ao fator educação que separa ainda mais as diferenças de classe e a ascensão social, além de ressaltar a influência da economia capitalista no campo educativo, não atendendo e oferecendo educação de qualidade para todos, não desenvolvendo as concepções sobre as condições impostas aos menos favorecidos, que são esmagados pela política, pela falta de acesso à saúde, pelas relações desiguais de classes sociais, e pelas demais dinâmicas presentes em nossa sociedade que contribuem para a continuidade desta situação para essa população.

A retórica neoliberal atribui um papel estratégico à educação e determina-lhe basicamente três objetivos:

1. Atrelar a educação escolar à preparação para o trabalho e para a pesquisa acadêmica como um imperativo do mercado ou às necessidades da livre iniciativa. Assegura, ainda, que o mundo empresarial tenha interesse na educação porque deseja uma força de trabalho qualificada, apta à competição no mercado nacional e internacional. Fala em nova vocacionalização, isto é, profissionalização situada no interior de uma formação geral, na qual a aquisição de técnica e linguagens de informática e conhecimento de matemática e ciência adquirem relevância. Valoriza as técnicas de organização, o raciocínio de dimensão estratégica e a capacidade de trabalho cooperativo. Apple (1999) afirma que na sociedade contemporânea, a ciência se transforma em capital técnico-científico. As grandes empresas controlam a produção científica e colocam-na a seu serviço de diversas formas: a) por meio da pesquisa científica industrial organizada na própria empresa; b) pelos controles das patentes, de produtos de tecnologia científica, podendo, portanto, se antecipar às tendências do "mercado" consumidor; c) controlando os denominados "pré-requisitos" do processo de produção científicaa escola e, principalmente, a universidade, onde se produz conhecimentos técnicocientíficos. A integração da universidade à produção industrial baseada na ciência e na técnica transforma a ciência em capital técnico-cientítico.

2. Tornar a escola um meio de transmissão dos seus princípios doutrinários. O que está em questão é a adequação da escola à ideologia dominante. Essa precisa sustentar-se, também, no plano das visões do mundo, por isso, a hegemonia passa pela construção da realidade simbólica. Em nossa sociedade, a função de construir a realidade simbólica é, em grande parte, preenchida pelos meios de comunicação de massa, mas a escola tem um papel importante na difusão da ideologia oficial. O problema para os neoliberais é que, nas universidades e nas escolas, durante as últimas décadas, o pensamento dominante, ou especular, conforme Alfredo Bosi (2001), tem convivido com o pensamento crítico nas diversas áreas do conhecimento e nas diversas práticas pedagógicas dialógicas, alternativas. Nesse quadro, fazer da universidade e da escola veículos de transmissão do credo neoliberal pressupõe um reforço do controle para enquadrar a escola, a fim de que cumpra, mais eficazmente, sua função de reprodutora da ideologia dominante.

3. Fazer da escola um mercado para os produtos da indústria cultural e da informática, o que, aliás, é coerente com a idéia de fazer a escola funcionar de forma semelhante ao mercado, mas é contraditório, porque, enquanto no discurso os neoliberais condenam a participação direta do Estado no financiamento da educação, na prática, não hesitam em aproveitar os subsídios estatais para divulgar seus produtos didáticos e paradidáticos no mercado escolar.

Revista HISTEDBR On-line, Campinas, n. Especial, p.147-161, mai.2009 - ISSN: 1676-2584 
Enquanto o liberalismo político clássico colocou a educação entre os direitos do homem e do cidadão, o neoliberalismo, segundo Silva (1999), promove uma regressão da esfera pública, na medida em que aborda a escola no âmbito do mercado e das técnicas de gerenciamento, esvaziando, assim, o conteúdo político da cidadania, substituindo-o pelos direitos do consumidor. É como consumidores, tanto no Brasil, como fora dele, que o neoliberalismo vê alunos e pais de alunos. Como observamos, a novidade, se é que assim se pode chamar, do projeto neoliberal para a educação não é só a privatização. $\mathrm{O}$ aspecto central é a adequação da escola e da universidade pública e privada aos mecanismos de mercado, de modo que a escola funcione à semelhança do mercado.

Isso tudo possui significado, pois antes dos objetos chegarem até nós, já passaram por uma longa cadeia de relações que "retirou pessoas da terra, causando sua ida para as favelas e negando aos seus filhos cuidados médicos e escolas" (COSTA, 1996). O senso comum e nossos modos de compreender as atividades cotidianas, dentro e fora da educação, dependem das relações sociais e das experiências vividas por cada um. As vantagens que obtemos do trabalho resultante de relações hierarquizadas em função do capitalismo são ocultadas nos currículos escolares. Não distinguimos os processos de dominação e subordinação em que vivemos, pois há uma criação do senso comum com a legitimação da dominação racial, de gênero e de classe, resultando em um caráter de nossa compreensão que tem origem nos modos pelos quais nos são apresentadas e cotidianamente estruturadas.

Assim, o individualismo, que é um dos ingredientes do ideário neoliberal, é um fenômeno que está muito disseminado nos dias atuais e muito presente nas nossas práticas e neste senso comum que nos é colocado hoje. O individualismo, de acordo com Durkheim (1895), ocorre quando o sujeito se orienta objetivando a satisfação de interesses cada vez menos coletivos e mais pessoais e individuais na disputa de sobrevivência na sociedade. Ele também dizia que a sociedade faz o homem na mesma medida que o homem a faz e, nesse sentido, a educação que nos é colocada procura nos ajustar aos padrões de nossa sociedade.

O âmbito educacional brasileiro reflete as mediações dialéticas existentes nos anos 1980 e 1990 que articulam as relações entre a educação, modernização e qualificação profissional. A influência do capitalismo fica evidente nas práticas educacionais que visam preparar mão-de-obra adequada para atender as necessidades do mercado, acompanhando o momento e desenvolvimento econômico do país. Nesse contexto, a educação profissional se apresenta como mecanismo de exclusão, considerando sua origem e trajetória marcada no Brasil por duas características: em primeiro lugar, esta sempre foi uma educação destinada aos subalternos da sociedade - à classe trabalhadora, e, em segundo, ter-se constituído, historicamente, em paralelo ao sistema regular de ensino. Esse quadro torna-se, ainda ,mais perverso quando consideramos que uma imensa maioria foi e está excluída até mesmo desta estrutura dual, ou seja, grande parcela da população que nem a esta "educação de classe" teve acesso, faz com que nos certifiquemos do caráter classista e discriminatório da sociedade brasileira.

Os empresários assumiram publicamente a defesa de um modelo de formação profissional mais moderno, mais adequado ao novo momento econômico do Brasil; o conceito de globalização da economia, assim como a questão da qualidade, tem ocupado um lugar de destaque nessa defesa pública do valor da educação. Princípios tradicionalmente pertencentes à classe trabalhadora e aos educadores progressistas, como a universalização da educação geral básica, são empenhados pela burguesia industrial (RODRIGUES, 1998). Dessa maneira, reformas educacionais foram implementadas com um duplo princípio: por um lado, voltadas 
para os princípios da empregabilidade, qualificação/treinamento/formação profissional, por outro, para o combate ao analfabetismo e a exclusão.

Ao analisarmos as políticas públicas para a educação ,na última década no Brasil, percebemos que esta não só tem-se caracterizado pelo aspecto irregular, fragmentário e compensatório, como também pelo afastamento do poder público quanto à definição e implementação de políticas que possam, efetivamente, garantir essa modalidade educativa.

Algumas ações do Ministério da Educação e do Ministério do Trabalho são desenvolvidas para garantir formação profissional por meio de cursos técnicos oferecidos por Instituições especializadas mantidas pelo Governo ou por Instituições credenciadas para oferecer cursos de formação profissional. Outros tipos de financiamento têm se apresentado, principalmente, com recursos do Ministério do Trabalho, Ministério da Educação e também do Fundo Nacional de Desenvolvimento da Educação (FNDE) para as áreas de capacitação de recursos humanos, aquisição de material escolar e reprodução de material didático.

É evidente que tal forma de lidar com o problema é insuficiente, além de inadequada, tendo em vista a amplitude da carência educacional da população jovem e adulta do País, sinalizando, pois, a inexistência de uma política eficaz para o enfrentamento da questão. Desse modo, percebemos que, nos anos 1990, a inauguração de um novo período na educação brasileira, comparável, em sua dimensão, às mudanças ocorridas a partir de meados dos anos 1960, de maneira semelhante, associavam educação às necessidades do setor produtivo - no entanto planejada sob os cuidados do télos do Brasil desenvolvido. Em outras palavras, da ideologia desenvolvimentista à ideologia competitivista, observamos que a educação passou de uma tentativa de adequar-se às exigências do padrão fordista para, após profunda reformulação, à tentativa de adequar-se ao referencial de flexibilização e globalização. Assim, se, ao longo dos anos 1960 e 1970, a Teoria do Capital Humano dominou fortemente a educação; na década de 1990, o que podemos perceber é que conceitos como competências e empregabilidade podem estar configurando um ressurgimento ou uma neo - teoria do Capital Humano.

No contexto da análise dessa ética empresarial o eixo principal divulgado pelos formadores dos trabalhadores parece ser a conscientização e a emancipação do sujeito aluno/trabalhador adulto na condição de sujeito social e coletivo. No entanto, esse argumento é frágil e percebe-se que fica apenas no campo do marketing empresarial do convencimento do trabalhador, tendo em vista que, o que se vê, de fato, é uma concepção de formação pautada pelo horizonte individualista e da submissão.

Finalmente, nossas análises apontam que a nova educação profissional brasileira e, particularmente, seu nível básico, orienta-se pelo conceito de empregabilidade. Como conseqüência, tem ocorrido um processo de individualização da formação do trabalhador, pelo qual se indica que cada um é responsável por buscar suas competências a serem alcançadas, segundo o discurso governamental, com o desenvolvimento das habilidades básicas, das habilidades específicas e das habilidades de gestão. Essas habilidades básicas seriam potencializadoras do empreendedorismo na economia "dada". Entretanto, o que de fato ocorre é, por um lado, um processo ideológico naturalizador da exclusão social e, por outro, a tentativa de redução do processo educativo a um mecanismo instrumental e adaptativo voltado para a integração periférica ou informal no mercado de trabalho.

Observa-se, pois, a configuração de uma proposta de formação para o trabalho que se propõe a estar totalmente separada da educação formal e escolarizada. O Estado, o 
empresariado e uma parcela dos trabalhadores ${ }^{1}$ justificam e defendem as reformas no sistema educacional como necessárias para uma maior competitividade industrial. A apologia à modernização tomou a educação como pedra de toque. $\mathrm{O}$ empresariado brasileiro, além de suas próprias ações na política de qualificação de seus empregados e da ampla mobilização pela educação básica, mais do que nunca, assumiram posição nas relações com o Estado, destacando a educação do trabalhador como condição fundamental para a qualidade e para a produtividade industrial.

Nesse quadro, a educação de qualidade emerge como uma demanda comum e urgente, apresentando-se como suposto elemento de convergência que se sobrepõe aos interesses mais distintos e característicos de grupos sociais diversificados e, muitas vezes, antagônicos (RUMMERT, 2000). Entende-se, pois, que a educação ainda se revela, no século XXI, restrita a um papel compensatório, apresentando-se - num momento marcado por incertezas, por diversas formas de precarização das condições de existência e por fortes processos de exclusão -, sob uma forma ideológica de "novo tipo", que constrói uma nova sociabilidade moldada pela lógica mercantil e que coloca sobre os indivíduos a responsabilidade pelo alcance de melhor qualidade de vida.

\section{REFERENCIAS}

ANDERSON, Perry. Balanço do neoliberalismo. In: SEDER, Emir \& GENTILI, Pablo. Pós-Neoliberalismo. Rio de Janeiro: Paz e Terra. 1995

ARANHA, A. V. S. O conhecimento tácito e a qualificação do trabalhador. Revista Trabalho e Educação. Belo Horizonte : v.1, n. 2, p. 12-30. 1997.

ARISTÓTELES. Metafísica, Tradução de Leonel Vallandro. Porto Alegre: Globo, 1969.

ARRIGHI, G. A Ilusão do Desenvolvimento. Petrópolis: Vozes, 1997.

BOBBIO, Norberto. Liberalismo e Democracia. São Paulo: Brasiliana. 1988.

BRYAN, Newton Antonio P. Educação, Trabalho e Tecnologia em Marx. Texto para Discussão. Campinas: Unicamp, FAE, DASE. mímeo. 39p.

CHESNAIS, François. O Capitalismo de Fim de Século, In: COGGIOLA et. alli. Globalização e Socialismo. São Paulo : Xamã, 1997. p. 7-34.

COSTA, Marisa Vorraber (Org.). Escola Básica na virada do século: cultura, política e educação. São Paulo: Cortez, 1996.

DREIFUS, R. A época das perplexidades: mundialização, globalização e planetarização: novos desafios. 2. ed. Petrópolis: Vozes, 1996.

DURKHEIM, E. Les règles de la méthode sociologique. Paris: Félix Alcan, 1895.

ESTEVÃO, C. V. Formação, gestão, trabalho e cidadania Contributos para uma sociologia crítica da formação. Educação e Sociedade. Revista de ciência em educação. Campinas, v 1; n.1, p.15-25, agosto. 2001.

${ }^{1}$ Ver FIDALGO (1999) e RUMMERT (2000).

Revista HISTEDBR On-line, Campinas, n. Especial, p.147-161, mai.2009 - ISSN: 1676-2584 
FERRETTI, C. J. Considerações sobre a apropriação das noções de qualificação profissional pelos estudos a respeito das relações entre trabalho e educação. Educação e Sociedade. Revista de ciência em educação. Campinas, 1; n.1, p.15-25, agosto. 2004.

GOUNET, Thomas. Fordismo e Toyotismo na civilização do automóvel. São Paulo:. Boitempo Editorial, 1999.

HAER, F.A. O caminho da Servidão. Rio de Janeiro: Instituto Liberal. 1990

HOBSBAWM, E. Era dos Extremos: o breve século XX (1914 - 1991). São Paulo: Cia das Letras, 1995.

HOLLOWAY, John. PELÁEZ, Eloína. Aprendendo a curvar-se: pós-fordismo e determinismo tecnológico. Revista Outubro. São Paulo, v.1, n. 2. p.21-30, setembro. 1998.

IANNI, O. A era do globalismo. Rio de Janeiro: Civilização Brasileira, 1996. . 3. ed. Rio de Janeiro : Civilização Brasileira, 1997..

1998.

Neoliberalismo e Nazi-fascismo. In: Revista Crítica Marxista v. 1. São Paulo: Xamã,

KANT, I. Crítica da razão pura. Coleção: Os Pensadores. Tradução de Valerio Rohden e Udo Baldur Moosburger. São Paulo: Abril Cultural, 1980.

LUCENA, Carlos. Aprendendo na Luta: A História do Sindicato dos Petroleiros de Campinas e Paulínia. - São Paulo : Ed. Publisher Brasil, 1997.

- Os desafios da formação educativa sindical frente ao neoliberalismo. Revista Educação Campinas, v.1, n. 3, p.51- 58,. julho. 1997.

- Tempos de destruição: educação, trabalho e indústria de petróleo no Brasil. Campinas: Autores Associados; Uberlândia: EDUFU, 2004.

Lucena, Carlos. Os Tempos Modernos do Capitalismo Monopolista: um estudo sobre a Petrobrás e a (des) qualificação profissional dos seus trabalhadores. Tese de doutorado, Faculdade de Educação, Campinas: Unicamp, 2001

MARX, K. Grundisse. In __. Obras Completas: conseqüências sociais do avanço tecnológico. São Paulo: Edições Populares, 1980.

Capítulo VI ( inédito) do Livro Primeiro de O Capital . São Paulo : Ciências Humanas, 1985.

. Elementos Fundamentales para la Crítica de la Economía Política (Grundisse) 1857

1858. 10. ed., v. 2. Cidade de México: Siglo Veintiuno Editores, 1985.

. Manifesto Comunista. São Paulo: Boitempo Editorial, 1998.

. O Capital: crítica da economia política. Livro $1^{\circ}$, v. I. Tradução Regis Barbosa e Flávio R. Kothe. 2. ed. - São Paulo: Ed. Nova Cultural, 1985.

O Capital: crítica da economia política. Livro $1^{\circ}$, v. II. Tradução Regis Barbosa e

Revista HISTEDBR On-line, Campinas, n. Especial, p.147-161, mai.2009 - ISSN: 1676-2584 
Flávio R. Kothe. 3. ed. , São Paulo: Ed. Nova Cultural, 1988.

O Capital: crítica da economia política. Livro $3^{\circ}$, v. VI. Tradução Reginaldo Sant' Anna. 3. ed.. São Paulo: Ed. Nova Cultural, 1984.

Miséria de la Filosofia. México: Siglo Veintuno Editores, 1987.

MELlO, A. F. Marx e a globalização. São Paulo: Boitempo Editoria, 1999.

NAPOLEONI, Cláudio. Lições sobre o capítulo sexto (inédito) de Marx. Tradução de Carlos Nelson Coutinho. São Paulo: Livraria Editora Ciências Humanas, 1981. p. 86-95

SALM, C. L. e FOGAÇA, A. Tecnologia, emprego e qualificação: algumas lições do século XIX. In: SALM, C. L. e FOGAÇA, A. Emprego e Desenvolvimento Tecnológico. São Paulo: Dieese, 1998.

SALM. C. Escola e Trabalho. São Paulo: Brasiliense, 1980.

SANTOS, E. H. Trabalho Prescrito e Trabalho Real no Atual Mundo do trabalho. Revista Trabalho e Educação. Belo Horizonte : v.1, n. 1, p. 13-27, junho, 1997.

SAVIANI, D. Sobre a Concepção de Politecnia. Rio de Janeiro: Fiocruz, 1989.

TADDEI, E. H. "Empregabilidade" e Formação Profissional: A "Nova" Face da Política Social da Europa. In: SILVA, H. S. A Escola Cidadã no Contexto da Globalização. São Paulo: Vozes, p. 340-367. 1999.

MARX, K. O Capital. Rio de Janeiro: Civilização brasileira, 1980.

MTE/ SEFOR. PLANFOR-Plano Nacional de Qualificação do Trabalhador. Brasília, 1998.

MTE/SEFOR. Educação profissional, um projeto para o desenvolvimento sustentado. Brasília, 1999.

PAULA, T.C. Proposta Pedagógica do Curso Técnico em Gestão de Atividades em Comércio e Serviços. Uberlândia, CENEX, 2005.

PAULA, T.C. Plano de Curso (Técnico para Gestão de Atividade em Comércio e Serviços). Uberlândia, CENEX, 2005.

POCHMANN, M. Educação e trabalho: como desenvolver uma relação virtuosa? Educação $e$ Sociedade. Revista de ciência em educação. Campinas, v.1, n.2, p.70-80, dezembro. 2004.

RODRIGUES, José dos S. O moderno príncipe industrial: o pensamento pedagógico da CNI. Campinas: Autores Associados, 1998.

RUMMERT, Sonia. M. Educação e Identidade dos Trabalhadores: concepções do capital e do trabalho. São Paulo: Xamã; Niterói: Intertexto, 2000.

\footnotetext{
${ }^{\text {i }}$ Professor do Programa de Pós-Graduação em Educação da Universidade Federal de Uberlândia. Coordenador do Grupo de Pesquisa História, Trabalho e Educação. Pesquisador da Fapemig.
}

Revista HISTEDBR On-line, Campinas, n. Especial, p.147-161, mai.2009 - ISSN: 1676-2584 
ii Professor do Programa de Pós-Graduação em Educação da Universidade Federal de Uberlândia - Membro do Grupo de Pesquisa História, Trabalho e Educação.

iii Professor do Programa de Pós-Graduação em Educação da Universidade Federal de Uberlândia - Membro do Grupo de Pesquisa História, Trabalho e Educação.

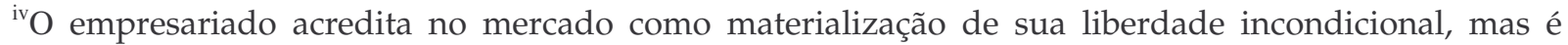
prisioneiro das suas deliberações, como se ele fosse movido por forças metafísicas e não por decisões humanas. Como bem afirma Mello (1999), o capital assume uma dimensão institucional que vai além do controle dos capitalistas, cidadãos ou Estados-Nação, impondo-se sobre esses como um poder autônomo, um fetiche, uma coisa, um sistema.

Artigo recebido em: 03/11/2008

Aprovado para publicação em: 21/01/2009

Revista HISTEDBR On-line, Campinas, n. Especial, p.147-161, mai.2009 - ISSN: 1676-2584 